\title{
HISTÓRIA
}

AS NARRATIVAS DAS BLOGUEIRAS:

A ESCRITA DE "SI" COMO EMPREENDIMENTO

Patrícia Carla Mucelin

\section{AS NARRATIVAS DAS BLOGUEIRAS: A ESCRITA DE "SI” COMO EMPREENDIMENTO}

\author{
THE BLOGGERS NARRATIVES: \\ THE WRITING OF "SELF” AS AN ENTERPRISE
}

Patrícia Carla Mucelin ${ }^{1}$

\begin{abstract}
RESUMO: As blogueiras brasileiras Camila Coelho e Camila Coutinho se profissionalizaram no campo da moda e na Internet. As transformações nas relações sociais e nas sensibilidades que os blogs propiciaram, contribuem para compreendermos as significações acerca do tempo presente ou de um passado muito recente. Seus blogs, respectivamente "Camila Coelho" e "Garotas Estúpidas", realizaram, através de narrativas sobre memórias pessoais, a representação da sua trajetória como escritas de "si". Foram analisados entrevistas e testemunhos das duas blogueiras como uma proposta de buscar subsídios para compreender as suas narrativas como potenciais constituidoras de subjetividade e espaços de memória. Para tanto, é necessário perceber os blogs como um espaço alternativo de escrita e expressão criativa do "eu".

PALAVRAS-CHAVE: História do Tempo Presente. Blogs. Narrativa. Memória.
\end{abstract}

ABSTRACT: The Brazilian bloggers Camila Coelho and Camila Coutinho became professional within the field of fashion and in the internet. The transformations in social relations and in the sensibilities that blogs provided, contribute to understand the significations about the present time or a very recent past. Their blogs, respectively "Camila Coelho" and "Garotas Estúpidas", performed through narratives about personal memories, the representation of their trajectory as writing of the self. Were analyzed Interviews and depositions of the two bloggers as a proposal to seek subsidies to understand their narratives as potential constituents of subjectivity and memory spaces. Therefore, it's necessary to notice the blogs as an alternative space of writing and creative expression of the self. KEY-WORDS: History of Present Times. Blogs. Narrative. Memory.

INTRODUÇÃO

\footnotetext{
${ }^{1}$ Doutora em História pelo Programa de Pós-Graduação em História da Universidade do Estado de Santa Catarina (UDESC). E-mail: patriciacarlamucelin@gmail.com.
} 


\section{HISTÓRIA}

AS NARRATIVAS DAS BLOGUEIRAS:

A ESCRITA DE "SI" COMO EMPREENDIMENTO

Patrícia Carla Mucelin

Ao pensar o meu objeto de pesquisa no contexto de uma história do tempo presente, não pude deixar de notar um fenômeno que impactou meu cotidiano, assim como o de muitas pessoas interconectadas nas redes mundiais de computação: as mudanças nas relações constituídas através da internet. Mudanças na forma de expressar as sensibilidades e subjetividades de cada um, na maneira inovadora como as redes articulam, como ocorreu no Brasil em Junho de 2013, movimentos políticos, ocupações e protestos como forma de exigir do poder público a melhoria de diversas situações socioeconômicas, culturais e políticas.

Ao acompanhar os blogs "Garotas Estúpidas", por Camila Coutinho, e "Camila Coelho", inteirei-me sobre o processo que acontecia para eleger as blogueiras da capa da revista Glamour Brasil, que seria publicada em julho de 2013. Na votação online, ambas as blogueiras, Camila Coelho e Camila Coutinho, estavam participando, juntamente com outras três mulheres: Thássia Naves, Helena Bordon e Lalá Rudge, cujos blogs levavam os nomes de suas autoras.

As blogueiras brasileiras Camila Coelho e Camila Coutinho se profissionalizaram no campo da moda e na Internet, especificamente a partir da publicação da edição de Julho de 2013 da revista Glamour, quando figuraram na capa e no conteúdo da edição, conferindo notoriedade e grande visibilidade aos seus blogs, que já eram páginas lucrativas e que se tornaram altamente conhecidos e divulgados, inclusive nas demais mídias. As transformações nas relações sociais e nas sensibilidades que os blogs propiciaram a partir do compartilhamento instantâneo de narrativas pessoais, em diversos formatos, contribuem para compreendermos as significações acerca do tempo presente ou de um passado muito recente, sobre moda, beleza e subjetividade. Pretendo aqui analisar como os seus blogs, respectivamente "Camila Coelho" e "Garotas Estúpidas", realizaram, através de narrativas sobre memórias pessoais, a representação da sua trajetória profissional como escritas de si. Foram analisados, para tanto, entrevistas, depoimentos e testemunhos das duas blogueiras, que foram encontrados em seus blogs e em sites da internet em formato de texto e de vídeo. 


\section{HISTÓRIA}

AS NARRATIVAS DAS BLOGUEIRAS:

A ESCRITA DE "SI" COMO EMPREENDIMENTO

Patrícia Carla Mucelin

Camila Coutinho e Camila Coelho escreveram e produziram material fotográfico e audiovisual sobre moda e beleza, e adquiriram um status de produtoras no campo da moda. Seus blogs desfrutaram de sucesso, principalmente devido ao grande número de seguidores e leitores, o que atraiu a atenção de grandes marcas e grifes que contataram as blogueiras em busca de parcerias, valorizando e investindo em seu trabalho em troca da divulgação de seus produtos e serviços.

Conforme assinala Hinerasky (2010, p. 35), embora pareça limitador relacionar o conceito dos blogs apenas a diários pessoais ou a uma escrita voltada para a autobiografia, é preciso levar em conta que eles fazem parte de uma rede cada vez mais complexa de dinâmicas múltiplas e heterogêneas. Os blogs podem, também ser comparados ao diário pessoal:

Quase todos os blogs, aliás, costumam recorrer a alguns dos artifícios estilísticos e ao modelo confessional do velho diário íntimo. Ou melhor: do diário éxtimo, de acordo com um trocadilho que procura dar conta dos paradoxos dessa novidade, que consiste em expor a própria intimidade nas vitrines globais das telas interconectadas. (SIBILIA, 2016, p. 20-21).

De acordo com Alexander Freund (2014, p. 227), a ascensão da narração de histórias como um novo fenômeno cultural ilumina o crescimento da cultura de massa da confissão no início do século XXI e está muito presente nos conteúdos publicados nos blogs, principalmente em formato audiovisual: "Apesar dos seres humanos sempre terem contado histórias, nunca as pessoas contaram tantas histórias sobre si próprias" (FREUND, 2014, p. 227). A produção deste tipo de material, compreendido também como expressão do comportamento social, traz em si uma abordagem sobre a vida cotidiana em evidência. Por conseguinte, justapõem-se os universos público e privado na elaboração de histórias sobre si, confessionais, como recursos frequentemente utilizados nos blogs, conjuntamente com informações de cunho jornalístico, pois a moda e o estilo pessoal dialogam com o estilo de vida que é divulgado.

Voltar o olhar para o conteúdo que produziram essas mulheres diz respeito a uma proposta de buscar subsídios para compreender as suas narrativas como potenciais constituidoras de subjetividade e espaços de memória. Para tanto, é 


\section{HISTÓRIA}

AS NARRATIVAS DAS BLOGUEIRAS:

A ESCRITA DE "SI" COMO EMPREENDIMENTO

Patrícia Carla Mucelin

necessário perceber os blogs como um espaço alternativo de escrita e expressão criativa do "eu", e através da criação de conteúdo de moda e beleza, que não parte, inicialmente, das mídias mais tradicionais, como a televisão, o rádio, as revistas ou os jornais.

\section{POSSIBILIDADES DE PESQUISA COM OS BLOGS}

Novas relações se estabeleceram entre internautas e produtores culturais, a partir do surgimento dos blogs de moda e beleza como uma ramificação da blogosfera, assim como marcas e empresas passaram a formar parcerias com as blogueiras no intento de obter uma divulgação significativa dos seus produtos e serviços. Desta maneira, os blogs "Camila Coelho" e "Garotas Estúpidas" criaram estratégias de poder ao incentivarem um consumo que promete um estilo de vida idealizado. As blogueiras se utilizaram da moda como símbolo de prestígio social, através de publicações que apresentavam, na maioria das vezes, escolhas de consumo. Da publicação do "look do dia" até as viagens e participações em grandes eventos, como lançamentos de marcas e grifes, e as semanas de moda, elas fizeram uma representação do seu cotidiano alinhada com as tendências de moda e beleza.

Foram analisadas publicações presentes nos blogs "Garotas Estúpidas" e "Camila Coelho", para compreender suas peculiaridades, histórias e características, através de um acervo de pesquisa realizado de Maio de 2015 a Dezembro de 2016. Matérias e entrevistas publicadas em sites da internet, em formato de texto ou de vídeo, foram importantes para preencher as lacunas que não foram respondidas apenas pelos conteúdos publicados nos blogs.

A historiadora Cristiani Bereta da Silva problematizou as possibilidades e limites com os quais se depara o historiador ao utilizar os blogs e sites como fontes históricas. Sobre as escritas de si na internet, a autora especifica que, nas análises, é necessário levar em consideração os possíveis deslocamentos que podem ocorrer no que se refere à condição de narrador do sujeito ou à experiência de si, pois: 


\section{HISTÓRIA}

\section{AS NARRATIVAS DAS BLOGUEIRAS: A ESCRITA DE "SI" COMO EMPREENDIMENTO \\ Patrícia Carla Mucelin}

Essas reflexões colocam desafios sobre a significação e interpretação do tempo pelos sujeitos do presente, da significação da sua existência, do que é público ou privado quando se trata da intimidade. Se essas mudanças podem ser percebidas nas narrativas digitais? Deve-se considerar aí a dimensão do descontínuo que a leitura na tela implica. Tal leitura constitui uma das "revoluções" da cultura escrita: transformar hábitos e percepções pela via da textualidade eletrônica. (SILVA, 2015, p. 33)

As possibilidades de utilização dos blogs na pesquisa história podem ser descritas abaixo:

O blog oferece acesso a todo um conjunto de informações e dados passíveis de identificar fontes e acervos de uso pelo historiador. Neste sentido, extrapola inclusive sua identificação enquanto fonte histórica, tendo em vista que vem a ser considerado uma ferramenta útil quanto a renovação metodológica. Tais dispositivos compreendem-se como plataforma de acesso a fontes e verdadeiros acervos temáticos, previamente organizados de forma inovadora e de contribuição a pesquisa histórica, enquanto fonte e reflexão específica. Essa forma de organização, remete a pensarmos o blog como uma espécie de "arquivo", com regularidades e referências preestabelecidas. A memória assim evocada, seria evidenciada pelas manifestações e posts previamente colocados pelo criador da ferramenta e indiretamente pelo público de acesso. As publicações/evocações de memória seriam acessadas a exemplo de um grande "álbum digital", armazenado na web. (OLIVEIRA e MUCELIN, 2017, p. 232-233).

Por conseguinte, ao utilizarem os blogs como acervos, os historiadores acabam assumindo a responsabilidade quanto a identificação, manutenção e suporte para que a análise desse material não se perca e como comprovação da autenticidade dos resultados de pesquisa desenvolvida. Por isso, foi realizada a criação e manutenção de bancos digitais, que oportunizaram o acesso aos documentos e fontes aqui consultados.

Ainda que apresentem um processo comunicativo diferente das mídias impressas, especialmente devido ao seu caráter de plataforma que permite o acesso a diferentes conteúdos em formato audiovisual, os blogs "Camila Coelho" e "Garotas Estúpidas" se tornaram, com o passar do tempo, verdadeiras empresas da web. Embora procurem sustentar o aspecto de diário pessoal com editoriais de "look do dia" que seguem a linha do "street style", eles agregam em sua estrutura a categorização de conteúdos de maneira similar ao das revistas de moda, porém com 


\section{HISTÓRIA}

\section{AS NARRATIVAS DAS BLOGUEIRAS: \\ A ESCRITA DE "SI" COMO EMPREENDIMENTO \\ Patrícia Carla Mucelin}

a peculiaridade de trazerem características de pessoalidade e intimidade com as leitoras:

A observação das novas redes de sociabilidade, identificadas nos registros dos blogs, passíveis de investigação na pesquisa, têm a contribuição direta da História do Tempo Presente como perspectiva de abordagem. As análises de comunidades que interagem a partir da cibercultura apontam para percursos teórico-metodológicos necessários a compreensão do passado recente e sua ressonância no presente, na interação dos historiadores com seus objetos de estudo. Os blogs são expressão deste potencial de pesquisa, ricos em termos de produção criativa e intelectual, articulando discussões e repercussões nas esferas cultural, política, econômica e social. (OLIVEIRA e MUCELIN, 2017, p. 234).

Uma das operações metodológicas necessárias para a realização dessa pesquisa, pensando os blogs como acervo, portanto, é a análise das narrativas, levando-se em consideração que boa parte do conteúdo encontra-se em formato de texto, ainda que possa ser breve e pontual. Dessa maneira, diz respeito à dedução das condições de produção e recepção das mensagens que os posts comunicam, partindo de indicadores variados (BRESCIANO, 2010, p. 73).

\section{BREVE HISTÓRIA DOS BLOGS}

Os blogs, "Camila Coelho" e "Garotas Estúpidas", tiveram um desenvolvimento a partir da sua criação, com mudanças que acompanharam o crescimento do número de leitores. O trabalho de especialistas, como assessores, colunistas, designers, fotógrafos, dentre outros, que passaram a fazer parte da equipe de cada uma das blogueiras com o tempo, agregaram características como apuramento técnico e certo nível de profissionalização, que diz respeito à facilidade de navegação pelas suas páginas. O requinte visual se desenvolveu através de imagens fotográficas produzidas a partir de uma preocupação estética e de um layout cada vez mais "limpo", ou seja, com menos informações visuais, o que permitia que o destaque maior fosse o conteúdo publicado. As características e uma breve história dos blogs foram descritas a seguir. 


\section{HISTÓRIA}

AS NARRATIVAS DAS BLOGUEIRAS:

A ESCRITA DE "SI" COMO EMPREENDIMENTO

Patrícia Carla Mucelin

Figura 1. Cabeçalho do blog "Garotas Estúpidas" de Maio de 2015.

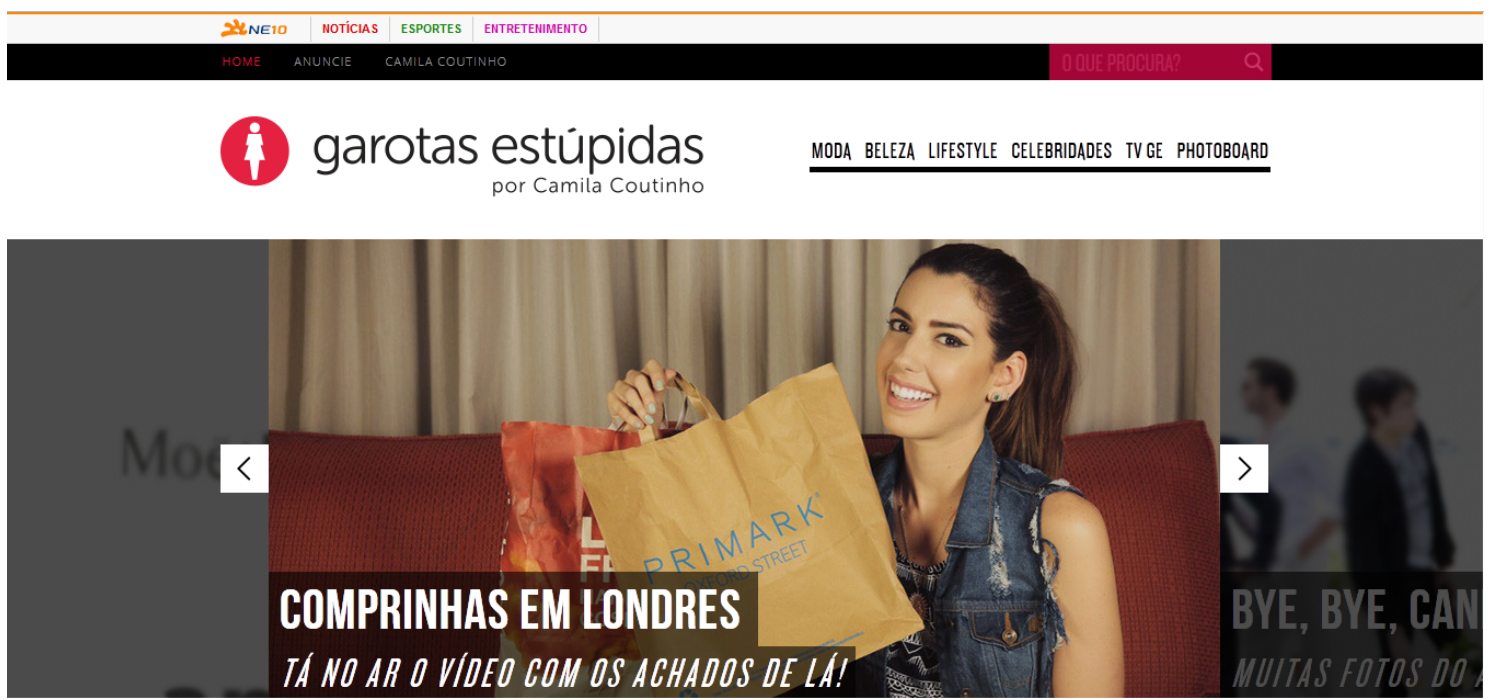

Fonte: Blog "Garotas Estúpidas". Disponível em <http://www.garotasestupidas.com/>. Acesso em dezembro de 2016.

Camila Coutinho Valença fundou seu blog em uma madrugada de 2006, quando era estudante de Design de Moda em Recife. Na época, ela gostava de ler artigos estrangeiros e divulgá-los para as suas amigas, pois, de acordo com a blogueira, em entrevista ${ }^{2}$ (PACCE, 2013), ainda não existiam blogs de moda nesse formato. Sua ideia então foi criar um espaço nesse segmento para se relacionar e falar diretamente com suas amigas:

Naquela noite, contudo, a então estudante de Design de Moda de Recife estava simplesmente decidida a substituir os e-mails de notícias compartilhadas com duas amigas por um espaço que reunisse o que elas mais gostavam de ler: os maiores bafões da época, como o último chilique da garota-problema Lindsay Lohan. Nascia, assim, o Garotas Estúpidas, blog pioneiro em moda no país. Foi batizado em homenagem ao single da cantora P!nk, Stupid Girls: uma brincadeira com a despretensiosa proposta de comentar tudo aquilo que faz parte do lado mulherzinha de todas nós em um lugar onde, como a própria Camila diz, "ninguém enchesse o saco". (TANCREDI, 2016).

\footnotetext{
${ }^{2}$ Os textos retirados de sites e blogs e aqui analisados como fontes históricas, foram citados tal qual se apresentavam na Internet, não sofreram revisão ortográfica, a fim de manter a originalidade da escrita.
} 


\section{HISTÓRIA}

AS NARRATIVAS DAS BLOGUEIRAS:

A ESCRITA DE "SI" COMO EMPREENDIMENTO

Patrícia Carla Mucelin

O nome escolhido se tornou a marca registrada de sua empresa, muitas vezes abreviado para a sigla "GE" nos textos do blog, diferentemente de Camila Coelho, que utilizava seu próprio nome.

Mas, afinal, o que faz com que Camila (Coutinho) tenha ganhado a
simpatia e o follow de tanta gente? Entre os possíveis motivos, a
personalidade sem frescura e gente como a gente, que transformou a
garota nada estúpida apaixonada por famosos em uma verdadeira
nativa do mundo das celebs. Também vale citar o estilo hi-lo da moça,
que mistura como ninguém o sapato comprado em dólares com
vestido de magazine - e que, claro, gera identificação imediata com o
público que não tem o closet recheado com Louboutins. E a fórmula,
à primeira vista simples, não poderia ter dado mais certo: transformou
o que era somente um blog em duas marcas, o site Garotas Estúpidas
e a persona Camila Coutinho. Passados nove anos, ela própria é hoje
sua maior criação e seu maior negócio. Além de grife disputada, seu
perfil pessoal supera o do GE em mais de 1 milhão de seguidores no
Instagram.
- Quando comecei o blog, nunca imaginei que Camila Coutinho ia virar
alguém que assina coisas, vai a eventos. Imaginei sempre o Garotas
Estúpidas como veículo. (TANCREDI, 2016).

Coutinho relata que demorou muito tempo para que tivesse um público considerável, pois, no início, ainda não contava com as redes sociais como complemento de divulgação. Com pouco mais de um ano, seu blog atingiu a visualização de 2 mil pessoas por dia. Ela então relatou a seu pai, o empresário Marcelo Valença, que Ihe aconselhou a comprar um domínio para si, bem como fazer um "desenho exclusivo" ou "layout". Ela contratou um rapaz que criou sua logomarca, a mesma que utilizava até 2016. Com a demanda, deixou de lado o trabalho com um estilista de Recife para se dedicar totalmente ao blog. Além de falar sobre celebridades, tema inicial, passou também a escrever sobre moda e beleza (TANCREDI, 2016).

Em entrevista, Camila Coutinho relata sobre o trabalho que realizava:

Lilian Pacce: Qual é a especialidade do seu blog?

(Camila Coutinho): Desde o início investi muito na diagramação dos posts, nas imagens. Sempre comprei muita revista importada pra me inspirar, aprendi Photoshop desde o começo e gosto de fazer montagens com as imagens. Além disso, tento dar um $360^{\circ}$, do superluxo de Paris ao fast-fashion, e tudo de maneira bem-humorada e simples. (PACCE, 2013). 


\section{HISTÓRIA}

AS NARRATIVAS DAS BLOGUEIRAS:

A ESCRITA DE "SI" COMO EMPREENDIMENTO

Patrícia Carla Mucelin

Já Camila Coelho, fundadora do blog que leva seu nome, é mineira, natural de Virginópolis, e passou a morar desde a adolescência em Boston, nos Estados Unidos. Começou a divulgar seu trabalho de maquiadora em seu canal no YouTube em 2010, quando conheceu o canal da americana Kandee Johnson e se interessou pela ideia dos tutoriais de maquiagem, que passou a empregar em seus vídeos, e através deles se tornou bastante conhecida (DOMINGUES, 2014). Após um ano de atividades no YouTube, devido a muitos pedidos de seguidores, iniciou o blog em Abril de 2011, que na época se denominava "Super Vaidosa". Devido à grande repercussão, seu marido, Ícaro Brenner Coelho, vendeu a sua parte de uma empresa que mantinha em Boston para administrar a carreira de Camila Coelho, que já se dedicava exclusivamente ao seu blog após seis meses do seu lançamento. Dessa maneira, Ícaro se tornou seu parceiro e apoiador na construção do empreendimento (LEMENTY, 2015).

Figura 2. Cabeçalho do blog "Camila Coelho" em maio de 2015.

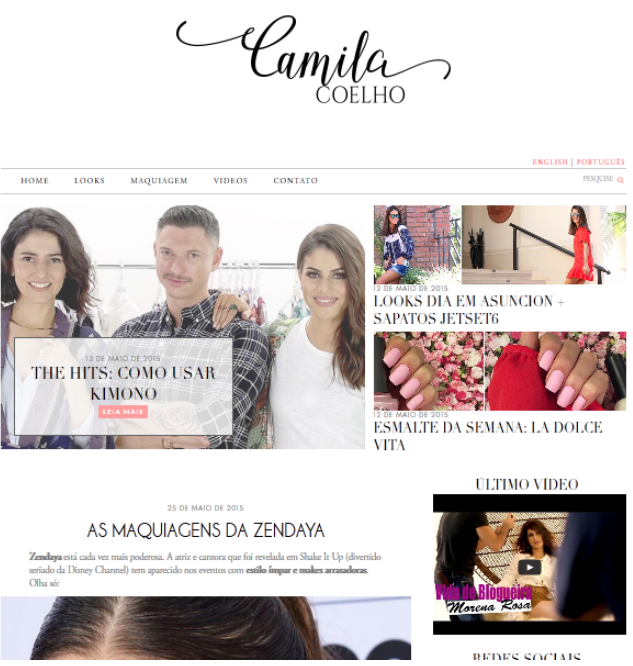

Fonte: Blog "Camila Coelho". Disponível em <http://camilacoelho.com/>. Acesso em dezembro de 2016.

Com um ano de atividades, seu sucesso chamou a atenção da empresária Alice Ferraz, fundadora da plataforma de blogs $F^{*}$ Hits, que convidou Camila Coelho para fazer parte da sua rede. A partir daquele momento, os aspectos como cuidados REHR| Dourados, MS | v. 12 | n. 24| p. 188-215 jul. / Dez. 2018 


\section{HISTÓRIA}

AS NARRATIVAS DAS BLOGUEIRAS:

A ESCRITA DE "SI" COMO EMPREENDIMENTO

Patrícia Carla Mucelin

com a imagem, parcerias e marketing passaram a ser administrados pela plataforma F*Hits (DOMINGUES, 2014). O blog, que até então era somente voltado para a beleza, passou a publicar conteúdos sobre moda e estilo de vida. Mudou seu título para "Camila Coelho" e, com a entrada no F*Hits, ganhou uma organização necessária para virar negócio, e a blogueira fundou outro canal no YouTube, dessa vez em inglês, voltado para a demanda do público estrangeiro.

Em um estudo de caso sobre Camila Coelho, Weschenfelder (2014, p. 02-05) afirma que a ideia de criar o blog partiu de uma interação realizada entre Camila e os fãs do YouTube e do Twitter, pois foram os pedidos de seus seguidores que levaram o "Super Vaidosa" a existir. Sua postagem inaugural deixou claro que compartilharia momentos pessoais com seus leitores, estabelecendo através de texto, fotografias e vídeos uma forma de contato com os fãs:

Nesta dinâmica - contatos entre produção e recepção - se constrói
uma processualidade que dá uma nova forma à expert, que vai sendo
transformada em celebridade. A blogueira se expõe ao outro através
de um complexo circuito midiático segundo operações que contam
com explícita adesão dos fãs. (WESCHENFELDER, 2014, p. 06)

Os blogs, como "Camila Coelho" e "Garotas Estúpidas", podem ser considerados, dentro da pesquisa histórica, como um importante espaço de memória e representação da contemporaneidade, bem como da complexidade histórica dos séculos XX e XXI. Dessa maneira, as publicações realizadas por eles constituem-se como um inesgotável conjunto de fontes documentais, apresentando um novo formato de acervo documental que pode ser compreendido como expressão da guarda da memória da sociedade atual (OLIVEIRA e MUCELIN, 2017, p. 223-224).

\section{UMA HISTÓRIA DO TEMPO PRESENTE}

Para realizar uma pesquisa que leve em consideração os usos, representações e recursos possíveis por meio dessa ferramenta chamada blog, cuja aplicação se estende a diversas formas de interação na sociedade contemporânea nos âmbitos político, econômico, artístico e social, é necessário levar em consideração 


\section{HISTÓRIA}

AS NARRATIVAS DAS BLOGUEIRAS:

A ESCRITA DE "SI" COMO EMPREENDIMENTO

Patrícia Carla Mucelin

que seus processos geram grandes repercussões, reverberando constantemente no tempo presente.

Para o historiador alemão Reinhart Koselleck, espaço de experiência e horizonte de expectativa são categorias históricas, embora não fossem por ele analisadas como conceitos da linguagem empregada das fontes: elas têm a capacidade de fundamentar a possibilidade de uma história, pois todas as histórias das pessoas foram constituídas pelas experiências vividas e pelas expectativas. Como categorias históricas, elas equivalem às categorias de espaço e tempo. Não se pode ter os conceitos "experiência" e "expectativa" um sem o outro (KOSELLECK, 2006, p. 307).

O historiador francês François Hartog, ao dialogar com Koselleck, afirma que o tempo histórico é produto da diferença entre o campo de experiência e o horizonte de expectativa, pois é gerado pela tensão entre as duas categorias, e é essa tensão ou distância que o regime de historicidade se propõe a esclarecer (HARTOG, 2015, p. 39). A hipótese do regime de historicidade permite que haja o questionamento sobre as relações que tecemos com o tempo ao longo da história. Dessa forma, o historiador pode acabar lidando com diversos tempos, realizando assim um vaivém entre o presente e o passado, que podem estar distanciados no tempo e no espaço. A articulação das categorias passado, presente e futuro possibilitam que se organizem as experiências, permitindo aos historiadores discuti-las (HARTOG, 2015, p. 37).

Um regime de historicidade é uma maneira de traduzir e ordenar experiências no tempo, ou seja, articular e dar sentido ao passado, presente e futuro. A sociedade pode contar apenas com o seu presente, mas existem estratégias para valorizá-lo, fechar-se nele ou se tentar sair dele, em proporções diferenciadas e variadas (HARTOG, 2015, p. 142).

Existe uma invasão em nosso cotidiano de um presente que é cada vez mais hipertrofiado, devido ao movimento rápido e às exigências da sociedade de consumo, na qual os avanços tecnológicos e a busca de benefícios cada vez mais rápidos tornam obsoletas as coisas e os homens. Assim, o tempo é visto como mercadoria e o consumo atual tende a valorizar o efêmero, como é o caso dos blogs, que estão 


\section{HISTÓRIA}

AS NARRATIVAS DAS BLOGUEIRAS:

A ESCRITA DE "SI" COMO EMPREENDIMENTO

Patrícia Carla Mucelin

diretamente organizados neste sentido: "Tomado no tempo do consumo, também o tempo se torna um objeto de consumo" (HARTOG, 2015, p. 160). Os blogs "Camila Coelho" e "Garotas Estúpidas" apresentam um conteúdo que, ao mesmo tempo em que deve acompanhar e representar as trajetórias pessoais de suas criadoras, também deve estar sintonizado com as últimas notícias e tendências da moda. Com textos curtos e pontuais, a narrativa é produzida para ser consumida o mais rápido possível, para abrir espaço para outros acontecimentos.

A mídia realiza o mesmo processo, pois é acelerada para o ao vivo, comprime o tempo ao produzir e consumir: recicla cada vez mais palavras e imagens, resumindo anos de história em poucos minutos (HARTOG, 2015, p. 148). Por conseguinte, o historiador do tempo presente deve criar estratégias para tomar a distância necessária para realizar a análise de objetos que ainda estão em processo de significação, fazem parte do passado e, no entanto, têm grande repercussão no presente, como os blogs de moda que estavam produzindo seu passado e futuro, continuamente em postagens cotidianas desde antes de 2013, momento em que as suas autoras, Camila Coelho e Camila Coutinho, apareceram na capa da revista "Glamour".

Outro instrumento presentista é o turismo: o mundo inteiro está ao alcance das pessoas muito facilmente através de um clique no computador ou mesmo através da televisão. Essa é uma das características mais significativas dos blogs, pois a realização de viagens pelas blogueiras diz respeito a um segmento de interesse sobre o qual procuram escrever e registrar em suas publicações, como podemos observar na publicação de Camila Coutinho no blog "Garotas Estúpidas":

Figura 3. Post "Segredos de Fashion Week: Fitting, equipe, street style, $\$ \$ \$ \ldots$... no blog "Garotas Estúpidas". 


\section{HISTÓRIA}

AS NARRATIVAS DAS BLOGUEIRAS:

A ESCRITA DE "SI" COMO EMPREENDIMENTO

Patrícia Carla Mucelin

\section{¿ Segredos de Fashion Week: Fitting, equipe, street style, $\$ \$ \$ \ldots$}

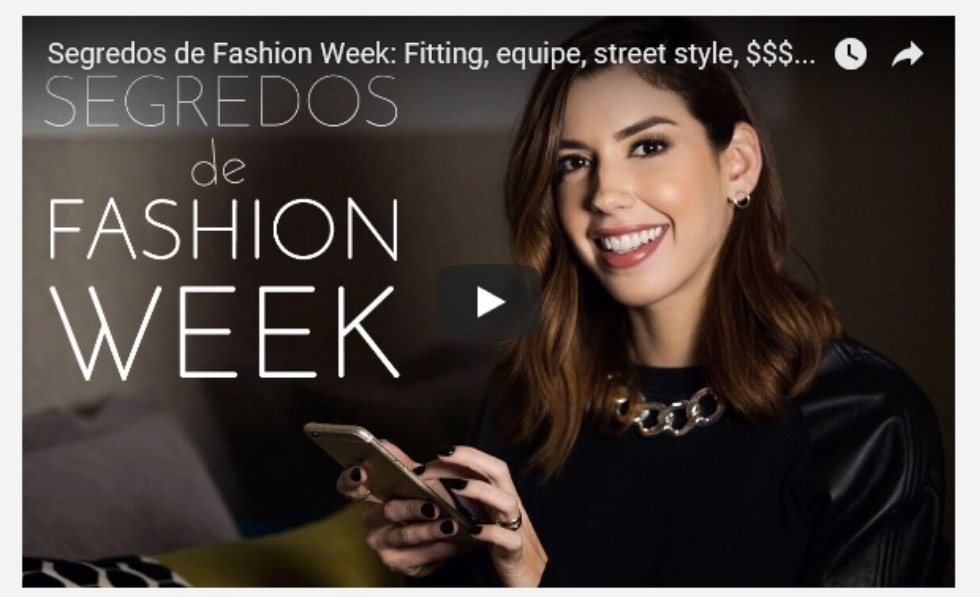

$O$ vídeo de hoje é um pouco diferente do que costumo fazer pro canal, mais numa pegada bate-papo pra responder as maiores dúvidas de vocês sobre... FASHION WEEKS! Já teve post aqui no blog contando vários bastidores sobre as semanas de moda, mas o assunto rende tanto (e confesso que gosto tanto de falar disso! hehe), que achei que merecia um vídeo especial!

Então quer saber o que é o tal do fitting, como conseguir convites, como fazer pra ser fotografada no street style? Só dar o play que falo sobre tudo isso e mais várias outras perguntas que vocês mandaram!

Fonte: Blog "Garotas Estúpidas". Disponível em < http://www.garotasestupidas.com/segredos-defashion-week-fitting-equipe-street-style/>. Acesso em dezembro de 2017.

Camila Coutinho contava com o apoio de uma equipe para divulgá-la nos eventos de "Fashion Week", uma assessora e uma fotógrafa (COUTINHO, 2016). A blogueira relatou que ia ao menos a duas semanas de moda por temporada, visando à produção de conteúdo para seu blog. Em seu vídeo, publicado no YouTube e divulgado através da publicação acima, Camila Coutinho esclarece sobre sua rotina de viagens nas semanas de moda:

Pra gente de blog, para que serve o Fashion Week? Eu fico brincando que é a novela da blogueira, porque é o momento da gente tipo, além de conferir as novidades, aparecer, conhecer mais as marcas, fazer relacionamentos com as marcas, com as pessoas, a imprensa 


\section{HISTÓRIA}

AS NARRATIVAS DAS BLOGUEIRAS:

A ESCRITA DE "SI" COMO EMPREENDIMENTO

Patrícia Carla Mucelin

internacional também, tem o street style, então é meio que uma vitrine (COUTINHO, 2016).

As blogueiras visam ao participarem em eventos como as Fashion Weeks, ou Semanas de Moda, e em campanhas publicitárias de determinadas marcas e empresas, divulgavam um estilo de vida no qual a possiblidade de conhecer qualquer lugar do mundo se constituía também como um desejo de consumo para suas leitoras.

De acordo com Hartog:

A economia midiática do presente não cessa de produzir e de utilizar o acontecimento, já que a televisão deu segmento ao rádio, porém com uma particularidade: o presente, no momento mesmo em que se faz, deseja olhar-se como já histórico, como já passado. Volta-se, de algum modo, sobre si próprio para antecipar o olhar que será dirigido para ele, quando terá passado completamente, como se quisesse "prever" o passado, se fazer passado antes mesmo de ter acontecido plenamente como presente; mas esse olhar é o seu, presente para ele. Essa tendência em transformar o futuro em futuro anterior pode chegar à caricatura. (HARTOG, 2015, p. 149-150)

Ou seja, o regime de historicidade presentista valoriza o imediato ao produzir o passado e o futuro de que necessita. Ao passo que temos uma história, a priori, midiática, também vivemos em um presente que deseja previsões, e, para tanto, os experts, como o são as blogueiras no campo da moda, são consultados a todo momento e, apesar dessa necessidade de saber e de controle, as sondagens erram e o futuro pode escapar (HARTOG, 2015, p. 150-151).

As técnicas de supressão do tempo, com a relevância da internet no cotidiano e a promoção do tempo real, são comportamentos do cotidiano que traduzem uma experiência compartilhada do presente nos blogs e demonstram que vivemos um período de obsessão pelo tempo, pois evidenciam a necessidade de liberá-lo ou tentar suprimi-lo, delineando assim um dos regimes de temporalidade do presente (HARTOG, 2015, p. 149).

\section{NARRATIVAS DIGITAIS: O ARQUIVAMENTO DA MEMÓRIA}




\title{
HISTÓRIA
}

AS NARRATIVAS DAS BLOGUEIRAS:

A ESCRITA DE "SI" COMO EMPREENDIMENTO

Patrícia Carla Mucelin

Por outro lado, "já inquieto, o presente descobre-se igualmente em busca de raízes e de identidade, preocupado com memória e genealogias" (HARTOG, 2015, p. 151-2). Da mesma maneira, a importância dos arquivos foi recuperada pelo tempo presente:

\begin{abstract}
Assim, esse presente, que reina aparentemente absoluto, "dilatado", suficiente, evidente, mostra-se inquieto. Ele queria ser seu próprio ponto de vista sobre si mesmo e descobre a impossibilidade de se fiar nisso [...]. Ele se mostra incapaz de preencher a lacuna, no limite da ruptura, entre o campo da experiência e o horizonte de expectativa. Escondido na sua bolha, o presente descobre que o solo desmorona sob seus pés. (HARTOG, 2015, p. 156).
\end{abstract}

Durante muito tempo, a história se desenvolveu em fusão com a memória para glorificar o passado e enaltecer a nação, visando desenvolver uma memória nacional. Com Halbwachs (2004, p. 85) e seus estudos sobre memória coletiva, começa a haver uma oposição entre história e memória, pois a função da história seria anular e erradicar a memória. Para Nora (1993, p. 7-28), a história do desenvolvimento nacional na França é o meio de memória por excelência. O autor, partindo da oposição entre memória e história - porém a partir de um contexto e uma linha completamente diferentes de Halbwachs, nos quais há uma supervalorização da memória e a defesa do fazer historiográfico -, a aceleração da história é quem provoca a destruição da memória. Para ele, fala-se tanto de memória justamente porque ela não existe mais. Há locais de memória porque não há mais meios de memória: são consagrados lugares a ela para preservar um sentimento de continuidade em relação ao passado. Enquanto a memória se vincula ao vivido, ligada à lembrança e ao esquecimento, a história é a reconstrução problemática e incompleta do que não existe mais. A primeira se liga ao presente e a segunda é a representação do passado. Para Nora, a postura crítica do historiador deve sempre suspeitar da memória, desejando destruí-la (NORA, 1993, p. 07-09).

Para Hartog, temos, no regime de historicidade presentista, uma memória arquivística, que se preocupa em fazer memória de tudo, contribuindo assim para a historicização cotidiana do presente. "Inteiramente psicologizada, a memória tornouse um assunto privado, que produz uma nova economia da 'identidade do eu'. 


\section{HISTÓRIA}

AS NARRATIVAS DAS BLOGUEIRAS:

A ESCRITA DE "SI" COMO EMPREENDIMENTO

Patrícia Carla Mucelin

'Pertence a mim [doravante] a atividade de lembrar-me e sou eu que me lembro'." (HARTOG, 2015, p. 162). Partindo de Nora, Hartog conclui que a memória é um instrumento presentista, pois não é mais o que se deve reter do passado para preparar um futuro desejado, mas é justamente o que faz com que o presente seja presente para si mesmo (HARTOG, 2015, p. 163).

De acordo com Hartog, é tarefa do historiador dos lugares de memória encontrar os lugares ativos, não para memorizar o seu discurso, mas devendo partir dos lugares para encontrar os discursos que os constituem como agentes, dos quais foram suporte. Assim, o lugar de memória é um "entroncamento" no qual se cruzam vários caminhos de memória, e somente estão vivos os lugares que são revisados, remodelados, pois o lugar de memória desativado ou esquecido não é mais do que a lembrança de um lugar (HARTOG, 2015, p. 165). Por conseguinte, podemos analisar os blogs através das considerações de Hartog sobre os lugares de memória, pois, enquanto plataforma digital que abriga acervos de memórias, necessitam que haja o agenciamento de seu conteúdo, que se mantenham vivos, retomados por meio da interação com os leitores e, mais que isso, que sejam regularmente atualizados e acessados. Assim também são as imagens que veiculam, sejam em fotografias ou audiovisual, pois elas só podem existir enquanto potenciais agentes ativos, ou seja, sua força reside no processo de comunicação permeado neste meio.

Os assuntos como beleza, bem-estar e comportamento são ferramentas de persuasão ao consumo nos discursos das blogueiras, mas também são assuntos relevantes para a representação das suas identidades através das suas narrativas textuais e imagéticas, podendo gerar identificação e admiração por parte de seus leitores. Portanto, os blogs não são apenas uma ferramenta para a construção de discursos, mas são parte de um processo criativo que permeia um sistema de comunicação diferenciado das demais mídias e, historicamente, são plataformas com capacidade de arquivar memórias pessoais que contribuem para o processo de representação da personagem blogueira:

Por tudo isso, certos usos dos dispositivos digitais para a comunicação em redes informáticas, como os aqui evocados, seriam estratégias que os sujeitos contemporâneos colocam em ação para responderem 


\section{HISTÓRIA}

AS NARRATIVAS DAS BLOGUEIRAS:

A ESCRITA DE "SI" COMO EMPREENDIMENTO

Patrícia Carla Mucelin

a essas novas demandas socioculturais, balizando outras formas de ser e estar no mundo. (SIBILIA, 2016, p. 48).

A Web 2.0 tem permitido, ao longo das últimas duas décadas, que várias atividades descritas como "confessionais" se desenvolvam, dando espaço para que qualquer pessoa que esteja conectada possa se apropriar das ferramentas disponíveis para expor publicamente o que, tempos atrás, era considerado como parte da intimidade: "A rede mundial de computadores se tornou um grande laboratório, um terreno propício para experimentar e desenvolver novas subjetividades e outras formas de se relacionar com os demais." (SIBILIA, 2016, p. 52-3)

Em 2013, Camila Coutinho relatou que era relevante para ela a escrita em primeira pessoa, de tal maneira que, durante os dez anos em que seu blog esteve ativo, com regularidade de publicação, ela mesma procurava escrever a maioria de seus posts, ainda que contasse com uma colaboradora e uma equipe de suporte para seus vídeos e projetos. Visando manter-se em primeira pessoa, Coutinho exaltou a necessidade de valorização da figura da blogueira:

Lilian Pacce: Quantos eventos por semana?

(Camila Coutinho) Viajo uma vez por semana, mas às vezes você emenda em outra coisa, como participar de uma foto. Tento ir em apenas um por semana senão não consigo pensar no conteúdo do blog. Você tem que ver coisas, viver, principalmente porque o veículo é em $1^{a}$ pessoa, é a nossa opinião que os leitores querem ver. (PACCE, 2013).

Em 2016, em uma matéria da revista "Elle", em seu site, sobre Camila Coutinho, é perceptível que a blogueira realizava seu trabalho com o intuito de produzir um material que permanecesse personalizado. E, embora também divulgasse muitas marcas parceiras, bem como as próprias linhas que lançou com algumas dessas marcas, como a Riachuelo e a Capodarte, existia uma preocupação latente em seu blog de agregar um conteúdo inusitado e diferenciado das demais mídias de seu segmento:

Se você pensa que há uma grande equipe no background de Camila, na verdade, ela cuida, com a ajuda de apenas uma pessoa, do conteúdo de dois Instagrams, que somados possuem 2,3 milhões de seguidores, Facebook, Snapchat, Twitter, canal no YouTube, 


\section{HISTÓRIA}

AS NARRATIVAS DAS BLOGUEIRAS:

A ESCRITA DE "SI" COMO EMPREENDIMENTO

Patrícia Carla Mucelin

Periscope (ela foi, olha só, a primeira a dar destaque à rede no Brasil) e dos posts diários no GE. (LEVY, 2016).

A experiência de "si" como um "eu" ocorre através da condição de narradora da blogueira, ao organizar e relatar a sua experiência na primeira pessoa do singular, mas não se expressa apenas através de suas palavras, ao traduzir em texto uma entidade que precederia o relato, tornando-se mais real que a história contada, " $E m$ vez disso, cabe admitir que a subjetividade se constitui na vertigem desse córrego discursivo, pois é nesse fluxo narrativo que o eu de fato se realiza" (SIBILIA, 2016, p. $58)$.

De acordo com Bruno Lima Oliveira, ocorre uma duplicidade temporal nos blogs, assim como nas redes sociais, na qual o indivíduo pode vivenciar a sua rotina e, ao mesmo tempo, construir uma identidade conforme a sua vontade e subjetividade:

Ambos os eus, o real e o virtual, ou melhor, o recalcado e o autoficcional, convivem simultaneamente. A coexistência de mais de um eu ocorre porque o sujeito contemporâneo é plural, fragmentado, híbrido e indefinível [...]. Nesse sentido, formalmente os blogs cumprem a contento a crítica à noção de sujeito, fragmentando sua narrativa em curtas cenas diárias e, muitas vezes, descontínuas. (OLIVEIRA, 2014, p. 103).

Portanto, na primeira pessoa dos blogs existe um eu performático, que pode narrar-se conforme seus anseios, sem ter que seguir a uma subjetividade pré-definida, possui liberdade para brincar com a fiç̧ão, ainda que esteja atrelada à realidade (OLIVEIRA, 2014, p. 104). Camila Coelho, por sua vez, também tinha a preocupação de cuidar do conteúdo do seu blog e, mesmo contando com a ajuda de alguns colaboradores, preferia escrever seus posts pessoalmente. As demandas de viagens e participação em diversos eventos, em consequência da crescente visibilidade, fizeram com que a blogueira deixasse de responder a todos os comentários do seu site e nas redes sociais, ritual que praticava com assiduidade no início do blog (LEMENTY, 2015).

No vídeo "Bate papo - Eu mudei?", Camila Coelho faz um relato sobre sua posição enquanto blogueira, em formato de confissão. A imagem a seguir traz a postagem feita em seu blog: 


\section{HISTÓRIA}

AS NARRATIVAS DAS BLOGUEIRAS:

A ESCRITA DE "SI" COMO EMPREENDIMENTO

Patrícia Carla Mucelin

Figura 4. Post "Bate papo: Eu Mudei!" no blog "Camila Coelho" 


\title{
HISTÓRIA
}

AS NARRATIVAS DAS BLOGUEIRAS:

A ESCRITA DE "SI" COMO EMPREENDIMENTO

Patrícia Carla Mucelin

18 DE ABRIL DE 2015

\section{BATE PAPO: EU MUDEI!}

\begin{abstract}
Oi amores!
O video de hoje é de Bate Papo, que inicia essa série de vídeos com "conversinhas" sobre assuntos aleatórios que terei com vocês de vez em quando, assim posso responder dúvidas, esclarecer certos assuntos e estar mais próxima de vocês!

Resolvi inaugurar o \#BatePapo com um assunto muito importante pra mim - a Minha Mudança (que tanto falam nas redes sociais). Será mesmo que eu mudei?

Confira o vídeo abaixo!
\end{abstract}

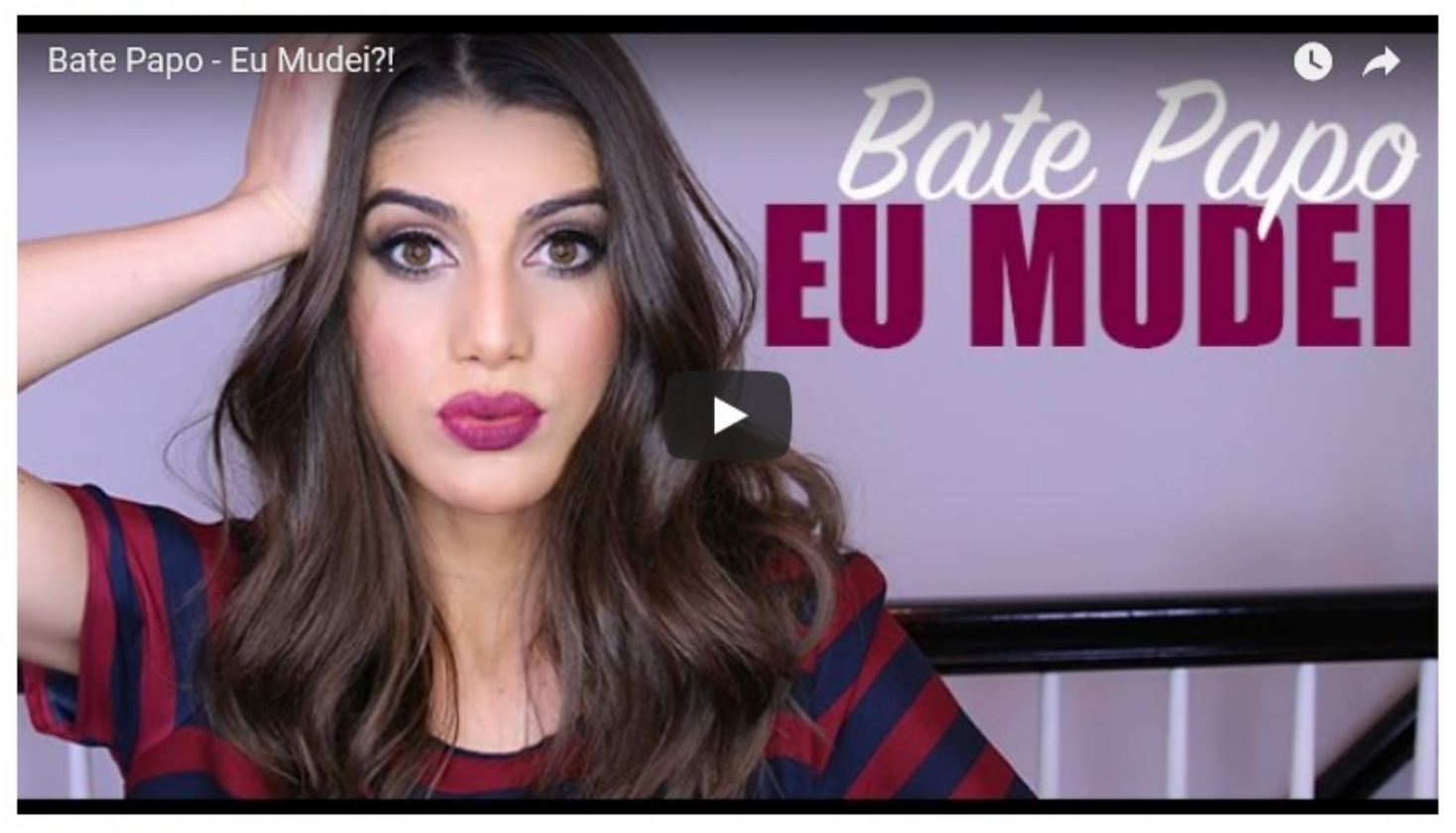

Gostaram?

Me deixem sugestốes de assuntos para o próximo bate papo!

Beijos

Fonte: COELHO, Camila. Bate Papo: Eu mudei!. Blog "Camila Coelho". 18 de Abril de 2015. Disponível em <http://camilacoelho.com/2015/04/18/bate-papo-eu-mudei/>. Acesso em dezembro de 2017.

A publicação inicia com um texto da blogueira, no qual ela descreve brevemente a intenção que teve ao publicar o vídeo, esclarecendo que, a partir dele, iria produzir uma série de vídeos para dialogar com as suas leitoras. Nos blogs, circula uma escrita com características da oralidade, pois tornou-se habitual o recurso a uma transcrição literal da fonética, e ao emprego do tom coloquial típico das conversações cotidianas. São textos que não se utilizam de parâmetros literários, não costumam remeter a outros textos: ocorre o descuido com as formalidades da linguagem e as REHR| Dourados, MS | v. 12 | n. 24| p. 188-215 jul. / Dez. 2018 


\section{HISTÓRIA}

AS NARRATIVAS DAS BLOGUEIRAS:

A ESCRITA DE "SI" COMO EMPREENDIMENTO

Patrícia Carla Mucelin

regras da escrita e pretendem ser mais breves, por isso não prezam pela perfeição (SIBILIA, 2016, p. 66): "Além disso, o tom coloquial da linguagem oral que impregna as escritas promove um excesso de informalidade verbal, que não cessa de espalharse sob a influência dessas novas formas de conversa digitada" (SIBILIA, 2016, p. 67). Assim, o texto de Camila, através da linguagem, procurava estabelecer uma relação íntima e descontraída com suas leitoras, tratando-as por "amores", convidando-as para assistirem ao vídeo e para estabelecerem um diálogo, quando pedia sugestões de assuntos para os próximos vídeos.

Uma "fome de realidade" tem se expandido nos últimos anos, incitando ao consumo de vidas alheias e relatos reais. A chamada "não-ficção" conquista, assim, um terreno que antes era ocupado por histórias de ficção de maneira quase exclusiva (SIBILIA, 2016, p. 61): "É preciso que os outros tenham acesso a esse universo antes preservado por sólidas paredes e rígidos pudores, pois o olhar alheio deve legitimar a existência disso que se mostra, quantificando seu valor com as diversas manifestações interativas" (SIBILIA, 2016, p. 62).

Existe uma necessidade em fixar o passado, em apreender o futuro, bem como em tomar distância em relação a si próprio (SILVA, 2015, p. 34). Essa necessidade de arquivar a própria vida está relacionada com as práticas das escritas de si, e permite que sujeitos como as blogueiras possam testemunhar suas experiências, se inventar e reinventar, e ao final fazer disso uma profissão:

Essas histórias foram pensadas como escritas de si, e, dessa forma, não foram tomadas nem como verdades e nem como ficções, mas sim como narrativas que integram por meio de referencialidades mútuas aspectos da vida vivida e da imaginação, da ficção. No sentido de que as escritas de si contêm aspectos do vivido, do que se imagina ter vivido, do que se queria ter vivido... [...] (SILVA, 2015, p. 34).

Falando diretamente com a câmera, em um vídeo gravado em sua casa, editado por ela mesma e publicado em seu canal do YouTube e na postagem do blog, Camila Coelho relata como o sucesso a atingiu e explica sobre suas frequentes viagens e queda de qualidade e número de publicações, frente às críticas que recebia nos comentários e redes sociais. 


\title{
HISTÓRIA
}

\section{AS NARRATIVAS DAS BLOGUEIRAS: A ESCRITA DE "SI" COMO EMPREENDIMENTO \\ Patrícia Carla Mucelin}

As críticas às quais a blogueira se refere são no sentido, não apenas do abandono ou queda de qualidade do conteúdo do blog, mas também sobre a sua fama, tais como falta de humildade e de interesse no público brasileiro ${ }^{3}$, o fato de utilizar peças de vestuários de grife que não são mais acessíveis à maioria das suas leitoras, e a diminuição na quantidade de vídeos publicados por ela em seu canal do YouTube. Ela se defende inicialmente, afirmando que, como figura pública, ela sabe lidar com as críticas e sabe que não vai conseguir agradar a todos. Ela afirma ainda que, mesmo muito ocupada pelas demandas do blog, está sempre tentando ler e acompanhar os comentários das suas leitoras:

\begin{abstract}
Mesmo com a correria, mesmo com tanta coisa pra fazer, eu dou um jeito de sempre estar lendo comentários. [...] Então, gente, olhando os comentários de um tempo pra cá, eu meio que ficava lendo e perguntando, mas porque que as meninas acham que eu mudei, o que eu tô fazendo... [...] e fui tentando me encontrar mesmo e encontrar a razão disso, porque não é só uma ou duas pessoas, não são só os haters que estão falando que eu mudei e tal, são realmente leitoras que me acompanham desde o início [...] eu descobri que vocês têm razão em um certo lado [...] eu com tanta correria, com a vida tão louca, tanta coisa pra fazer, tanta viagem, quase não parando em casa, eu acabei me distanciando de vocês. (COELHO, 2015).
\end{abstract}

Consequentemente, ela admite que se distanciou das suas leitoras e que mudou em alguns aspectos, pois amadureceu e fez parte de novas vivências; a seguir, Camila explica a sua nova rotina, que mudou em relação aos primeiros anos do blog, pois, com as viagens a trabalho, seu tempo para criação de conteúdo era mais limitado. Ela também afirma que sua vida é "corrida" porque não pretende dizer não para as oportunidades que surgem, como a participação em campanhas, ser garota propaganda de marcas conhecidas ou participar de semanas de moda:

Aí as pessoas perguntam: "mas pra quê viajar tanto?" O engraçado é que muita gente acha que as minhas viagens são a passeio, são viagens para me divertir e que parece que eu estou sempre de férias. Mas não, gente, hoje as minhas viagens [...] são a trabalho e nessas viagens é quando meu trabalho é dobrado, [...] durante semanas de moda é assim, o tempo inteiro, o dia inteiro cheio de compromissos e

\footnotetext{
${ }^{3}$ Isso porque suas parcerias nos Estados Unidos, país em que reside, como a empresa $F^{*} H i t s$, a levaram a produzir conteúdo em inglês para o blog, geralmente voltado para leitores americanos ou estrangeiros.
} 


\section{HISTÓRIA}

AS NARRATIVAS DAS BLOGUEIRAS:

A ESCRITA DE "SI" COMO EMPREENDIMENTO

Patrícia Carla Mucelin

a noite [...] é esse tempinho que eu tenho ali no final do dia [...] pra fazer conteúdo para vocês. Então eu trabalho o dia inteiro, seja $(\mathrm{m})$ experiências maravilhosas ou não, eu "tô" trabalhando. (COELHO, 2015).

Por outro lado, Camila Coelho ressalta que, apesar de ter uma pequena equipe que ajuda a produzir material sobre moda e beleza, ela não quer deixar de trabalhar com isso, pois para ela o blog tem grande importância. Por fim, ela fala que a vida glamorosa que as pessoas vislumbram pelo blog ou pelas mídias sociais é o seu trabalho e, apesar de ter muito da sua vida pessoal, ela se considera uma "menina normal" como as suas leitoras:

Eu filtro muito, e eu tento muito controlar as minhas viagens porque eu também não quero ficar só viajando, a minha vida ser fora, eu gosto de estar em casa e eu preciso desse tempo também pra vocês, pro blog. [...] porque eu nunca quero deixar de fazer o blog [...] mas eu quero sempre estar ali, ter a minha mão ali no blog, a minha personalidade, a minha pessoa ali no blog, [...] eu tenho uma pequena equipe e eu poderia sim largar tudo na mão de alguém pra fazer isso pra mim, mas não, eu quero tá ali presente. (COELHO, 2015).

As imagens foram captadas através de sua câmera pessoal e filmadas em sua própria casa. É possível perceber que o vídeo foi pouco editado e que a blogueira optou por mantê-lo como um depoimento longo, com muitas repetições na sua fala, num intuito de ser uma conversa informal com os seus leitores e seguidores. O vídeo quase passa a impressão de ser uma conversação em tempo real.

Em seu vídeo, em formato de "bate-papo", Camila Coelho fez uma série de esclarecimentos que envolvem suas escolhas pessoais em relação à sua profissão de blogueira e sua mudança após o sucesso de seu blog, como uma maneira de se reportar frente às críticas que recebeu, o que evidencia o aspecto dialógico do discurso, que foi feito como uma resposta às críticas das leitoras. Mas esse formato de vídeo também diz respeito a uma estratégia muito utilizada pelas blogueiras de moda e beleza no geral, de utilizar o relato pessoal como um recurso para atrair a atenção do seu público alvo ao atender a uma demanda específica de trazer conjuntamente com as informações de moda e beleza, os detalhes acerca da vida privada como parte integrante desse conteúdo. 


\section{HISTÓRIA}

AS NARRATIVAS DAS BLOGUEIRAS:

A ESCRITA DE "SI" COMO EMPREENDIMENTO

Patrícia Carla Mucelin

No caso do depoimento de Camila Coelho, o "eu" e seus enunciados podem ser considerados como heterogêneos, pois estão sempre habitados e dependentes da alteridade, afinal, toda comunicação requer a existência de um "outro", razão pela qual todo discurso é dialógico e polifônico (SIBILIA, 2016, p. 58): "É justamente nesses discursos autorreferentes, aliás, que a experiência da própria vida ganha forma e conteúdo, adquire consistência e sentido ao se cimentar em torno de um eu.". Ainda nesse ínterim:

A experiência vital de cada sujeito é um relato que só pode ser pensado e estruturado como tal se, de algum modo, for cristalizado na linguagem. Contudo, aqui tampouco se trata de dar um formato discursivo a uma realidade prévia: assim como ocorre com o seu personagem principal, esse relato não representa simplesmente a história que se tem vivido, mas ele a apresenta. E, de alguma maneira, também a realiza, concede-lhe consistência e sentido, delineia seus contornos e a constitui. (SIBILIA, 2016, p. 59).

Por essas narrativas tecerem a vida que a blogueira vai levando, são responsáveis por realizá-la. As escritas de "si" podem ser reconhecidas como objetos privilegiados, pois nos permitem compreender não apenas a constituição do sujeito na linguagem, mas também como a vida se estrutura como relato, em seus mais diversos formatos (SIBILIA, 2016, p. 61). Assim como as formas de narrar mudam com o tempo e os avanços tecnológicos, acompanhando os avanços históricos na produção de subjetividades, as novas versões de relatos sobre o eu apresentam o "eu" e a "vida" como entidades fluidas e geralmente inapreensíveis, cada vez mais enaltecidas e espetacularizadas (SIBILIA, 2016, p. 61).

\section{CONSIDERAÇÕES FINAIS}

Entendo a figura da blogueira como uma personagem, porque existe uma diferenciação entre a representação feita pelas blogueiras na web e quem elas são empiricamente, de tal maneira que suas publicações passam por filtros para mostrar apenas os melhores aspectos de seus cotidianos. Tudo bem, todos nós fazemos isso nas redes sociais e na internet no geral; porém as blogueiras fazem dessa espetacularização das suas vidas a sua profissão: elas seguem modelos baseados REHR| Dourados, MS | v. 12 | n. 24| p. 188-215 jul. / Dez. 2018 


\title{
HISTÓRIA
}

\author{
AS NARRATIVAS DAS BLOGUEIRAS: \\ A ESCRITA DE "SI" COMO EMPREENDIMENTO \\ Patrícia Carla Mucelin
}

em como se constituiu a cultura de massa da confissão, as entrevistas desde a era da televisão, se apropriam desse escopo que aprenderam para desenvolver uma narrativa própria, centrada na representação do eu como figura de máxima importância, a de "digital influencers".

Os blogs podem remeter a uma:

[...] velha necessidade que diz respeito às práticas de escritas de si: necessidade de fixar o passado e também apreender o futuro, necessidade de tomar distância em relação a si próprio, necessidade de arquivar a própria vida, de testemunhar, de se inventar e reinventar." (SILVA, 2015, p. 33-34)

As histórias pensadas como escritas de "si" não devem ser tomadas nem como verdades nem como ficções, mas como narrativas que integram aspectos das vivências, assim como da imaginação e da ficção (SILVA, 2015, p.34). Por apresentarem aspectos do vivido, do que se desejou ter vivido e do que se imagina ter vivido, as blogueiras, como narradoras de si, constroem um personagem que se encontra distante do "eu empírico" (SILVA, 2015, p.34).

As trocas comunicativas entre os leitores e as blogueiras não ocorrem, no caso dos blogs "Camila Coelho" e "Garotas "Estúpidas", nos espaços dedicados a comentários nos blogs, mas sim, e principalmente, através das redes sociais no geral, nas quais seus leitores apresentam suas dúvidas, insatisfações, demandas e elogios, e as blogueiras, através desses comentários, procuram sintetizar e responder através de publicações em formato de texto e vídeo, como nos casos estudados. Isso demonstra que existe uma tentativa dessas mulheres de fortalecerem as suas próprias imagens como blogueiras, através de uma relação mais íntima com os leitores e seguidores, pois os seus blogs deixaram de se tornar diários pessoais de divulgação dos acontecimentos cotidianos para se tornarem empresas, páginas com retorno lucrativo considerável. Porém a dedicação aos blogs enquanto profissão implica em uma união, ou até mesmo quebra da barreira entre o público e o privado, como vimos na análise do depoimento de Camila Coelho, por meio de narrativas pessoais como forma de trabalho das blogueiras:

Contudo, em princípio, nota-se que essas novas narrativas autorreferentes não parecem enfatizar a função do narrador, e nem a 


\title{
HISTÓRIA
}

\author{
AS NARRATIVAS DAS BLOGUEIRAS: \\ A ESCRITA DE "SI" COMO EMPREENDIMENTO \\ Patrícia Carla Mucelin
}

do autor, mas a do seu protagonista. O acento recai naquele prezado personagem que se chama eu. Mais uma confirmação da morte do narrador benjaminiano, pois os sujeitos desses relatos publicados na internet se definem como alguém que é; alguém que vive a própria vida como um verdadeiro personagem. (SIBILIA, 2016, p. 82).

De acordo com Sibilia (2016, p. 57), os usos confessionais da internet se enquadram em uma categoria na qual seriam manifestações renovadas dos conhecidos gêneros autobiográficos, afinal, o "eu" que se mostra nas telas da rede costuma ser de natureza tríplice, pois é ao mesmo tempo narrador, autor e personagem: "Além disso, e pelo menos em certa medida, não deixa de ser uma ficção; pois, apesar de sua contundente autoevidência, é sempre frágil o estatuto do eu" (SIBILIA, 2016, p. 57). Para a autora, é inegável que se trata de um tipo muito especial de ficção:

Além de desprender do magma real da própria existência, acaba provocando um forte efeito no mundo: nada menos do que um eu, um efeito-sujeito. É uma ficção necessária, portanto, já que somos feitos desses relatos: eles são a matéria que nos constitui enquanto indivíduos com um nome, uma trajetória e uma identidade. Nesse sentido, somente a linguagem nos dá consistência e relevos próprios, pessoais, singulares, e a substância que resulta desse cruzamento de narrativas se (auto)denomina eu. (SIBILIA, 2016, p. 57).

De acordo com Machado (2013, p. 14), inicialmente os jornalistas começaram a se apropriar da ferramenta do blog como suporte para exprimir opiniões que não se enquadravam em outras mídias, pois não necessitavam de filtros ou edições. Desta maneira, os blogs exprimiam o conceito de um espaço de expressão personalizado, no qual a legitimação da opinião remetia às características de diários pessoais. Entretanto, é a interação com o público leitor que legitima a função comunicativa dos blogs, pois através deles o público cria identificações e realiza trocas comunicativas concernentes ao conteúdo postado nessa ferramenta virtual.

\section{REFERÊNCIAS}

BRESCIANO, Juan Andrés. La historiografía en el amanecer de la cultura digital. Montevideo: Ediciones Cruz del Sur, 2010. 


\title{
HISTÓRIA
}

\author{
AS NARRATIVAS DAS BLOGUEIRAS: \\ A ESCRITA DE "SI" COMO EMPREENDIMENTO \\ Patrícia Carla Mucelin
}

COELHO, Camila. Bate Papo: Eu mudei!. Blog Camila Coelho. 18 de Abril de 2015. Disponível em <http://camilacoelho.com/2015/04/18/bate-papo-eu-mudei/>. Acesso em dezembro de 2017.

COUTINHO, Camila. Segredos de Fashion Week: Fitting, equipe, street style, $\$ \$ \$ \ldots$ Blog Garotas Estúpidas. 31 de Março de 2015. Disponível em $<$ http://www.garotasestupidas.com/segredos-de-fashion-week-fitting-equipe-streetstyle/>. Acesso em dezembro de 2017.

DOMINGUES, Marina. Camila Coelho: como nasce uma blogueira de sucesso. Estadão. Vida \& Estilo Moda. Setembro de 2014. Disponível em <http://vidaestilo.estadao.com.br/noticias/moda,camila-coelho-como-nasce-uma-blogueira-desucesso,1558508>. Acesso em dezembro de 2016.

DOSSE, François. Renascimento do Acontecimento. São Paulo: Unesp, 2013.

FREUND, Alexander. "Os animais que confessam": Contribuição para uma história de longa duração da entrevista de história oral. Revista tempo e argumento. Florianópolis, v. 06, n. 13, p. 203-239, 2014.

HALBWACHS, Maurice. A memória coletiva. São Paulo: Centauro, 2004.

HARTOG, François. Regimes de historicidade: Presentismo e experiências do tempo. 1. ed. 2. reimp. Belo Horizonte: Autêntica, 2015.

HINERASKY, Daniela Aline. O fenômeno dos blogs street-style: do flâneur ao "star blogger". Porto Alegre, 2012. Tese. Programa de pós-graduação em Comunicação Social. Pontifícia Universidade Católica do Rio Grande do Sul, 2012.

KOSELLECK, Reinhart. Futuro Passado: contribuição à semântica dos tempos históricos. Rio de Janeiro: Contraponto: Ed. PUC Rio, 2006.

LEMENTY, Anna Carolina. Make-up free. Revista Estilo. Edição 149. Fevereiro de 2015 (digitalizada). Disponível em <http://camilacoelho.com/clipping/ >. Acesso em dezembro de 2015.

LEVY, Nathalia. "Os blogs precisam se especializar e oferecer conteúdo e embasamento", diz Camila Coutinho. Revista Elle. Julho de 2016. Disponível em <http://elle.abril.com.br/moda/os-blogs-precisam-se-especializar-e-oferecerconteudo-e-embasamento-diz-camila-coutinho/>. Acesso em dezembro de 2016.

MACHADO, Wladimir Silva. Do podrinho ao vintage: a visualidade nos blogs de moda e a publicidade em imagens de look do dia. Goiânia, 2013. Dissertação. Programa de pós-graduação em Arte e Cultura Visual. Universidade Federal de Goiás. 


\section{HISTÓRIA}

AS NARRATIVAS DAS BLOGUEIRAS:

A ESCRITA DE "SI" COMO EMPREENDIMENTO

Patrícia Carla Mucelin

NORA, Pierre. Entre memória e história. A problemática dos lugares. Revista Projeto História. São Paulo: v. 10, p. 7-28, dez. 1993.

OLIVEIRA, Bruno Lima. Blogs: constituição de si e memória do presente - nova forma de labor literário. In: OSWALD, DO COUTO, WORCMAN (orgs.). Narrativas digitais, memórias e guarda. Curitiba: CRV, 2014.

OLIVEIRA, Márcia Ramos de; MUCELIN, Patrícia Carla. Os blogs sob o olhar do historiador. In: RODRIGUES, Rogério Rosa (Org). Possibilidades de pesquisa em história. São Paulo: Contexto, 2017.

PACCE, Lilian. Blogueira \& empresária: Camila Coutinho. Plataforma Lilian Pacce. Dezembro de 2013. Disponível em <http://www.lilianpacce.com.br/moda/blogueira-eempresaria-camila-coutinho/>. Acesso em dezembro de 2016.

SIBILIA, Paula. O show do eu: A intimidade como espetáculo. Rio de Janeiro: Contraponto, 2016.

SILVA, Cristiani Bereta da. Narrativas digitais sobre os exames de admissão ao ginásio: ego-documentos e cultura escrita na história do tempo presente. Revista Tempo e Argumento, Florianópolis: v. 7, n.15, p. 5-41. Maio/ago. 2015.

TANCREDI, Thamires. Entrevista! Blogueira de moda mais influente do Brasil, Camila Coutinho fez de seu nome uma grife. Revista Donna. Janeiro de 2016. Disponível em <http://revistadonna.clicrbs.com.br/moda/entrevista-blogueira-demoda-mais-influente-brasil-camila-coutinho-fez-de-seu-nome-uma-grife/>. Acesso em julho de 2016.

WESCHENFELDER, Aline. Transformações da expert em celebridade: O caso Camila Coelho. In: Colóquio Semiótica das Mídias, 3, 2014, Japaratinga. Anais. Japaratinga: Centro Internacional de Semiótica e Comunicação. 2014. p. 1-13.

Artigo recebido em 24/07/2018

Artigo aceito em 15/10/2018 